\title{
Effect of Gamma Radiation on the Adsorption Capacity and Regeneration / Desorption of Sulphate and Phosphate lons Using Smart Hydrogel.
}

Mona Eid ( $\sim$ mona_eid2000@yahoo.com )

National Center for Radiation Research and Technology https://orcid.org/0000-0002-2960-1884

Magda Elarnaouty

Alexandria University

Mohamed Hassouna

Alexandria University

Afaf Hafez

Alexandria University

Mohamed Salem

Alexandria University

\section{Research Article}

Keywords: Radiation, Epichlorohydrine, Adsorption, Anions, Wastewater

Posted Date: December 15th, 2021

DOI: https://doi.org/10.21203/rs.3.rs-1128915/v1

License: (9) This work is licensed under a Creative Commons Attribution 4.0 International License.

Read Full License 


\section{Abstract}

Co-polymeric hydrogels containing poly (Acrylamide /Epichlorohydrine) $\mathrm{P}(\mathrm{AAm} / \mathrm{EPI}$ ) with different acrylamide and Epichlorohydrine content were fabricated by gamma radiation at different irradiation doses as adsorbent materials for wastewater treatment. The mechanisms of radiation-induced crosslinking of hydrogel in aqueous solution has been evaluated. The gel contents and the swelling/diffusion kinetic parameters were evaluated at different irradiation doses, and the result confirm a non-fichian mechanism. The shape, surface morphology, and porosity of P (AAm/ Epi) hydrogel were characterized by scanning electron microscope (SEM). Adsorption experiments were carried out for the removal of sulphate and phosphate ions from wastewater using $\mathrm{P}(\mathrm{AAm} / \mathrm{EPI})$ hydrogels as adsorbent materials. The isotherm data were analyzed by Freundlich equation. The equilibrium isotherm results show a better fitting $(\mathrm{R} 2>0.9)$ to the Freundlich model for all anions. The calculated regeneration efficiency (\%) values of sulphate and phosphate ions found to be ranged between $63.2(\%)$ and 46 $(\%)$.The relatively higher regeneration efficiency (\%) and keeping the hydrogels its shape without any deformation promising to use the same hydrogels further times which decrease the economic cost.

\section{Introduction}

Industrial water, even natural water, is often contaminated by toxic, or sometimes, carcinogenic impurities, causing ecological disequilibrium and dreadful health disorders in humans. The major sources of water pollution can be attributed to discharge of untreated sanitary and toxic industrial wastes, and run off from agricultural fields, and so on. The majority of pollutants discharged in wastewaters can be toxic to aquatic life and can cause natural waters to be unfit as potable water sources. There are several causes of water pollution organic, inorganic as well as municipal, industrial, and agricultural (1).

Sulphate is a common constituent of many natural waters and wastewaters, and is sometimes present in high concentrations. Industrial wastewaters are responsible for most anthropogenic emissions. The damage caused by sulphate emissions is not direct, since sulphate is a non-toxic compound. However, high sulphate concentrations can unbalance the natural sulphur cycle.

Phosphorus as an essential element for the growth of living organisms is widely used in the areas of agriculture and industry. However, excessive discharge of phosphate into water bodies such as lakes, lagoons, rivers and inland seas, may cause detrimental eutrophication. Thus, it is important to control the concentration of phosphorous in water to avoid eutrophication. Phosphorus is found as phosphate $\left(\mathrm{PO}_{4}{ }^{3-}\right)$ in nature and present as orthophosphate, polyphosphate and organic phosphate in water. In addition, phosphates are also found abundant in the wastewater from laundering agents for examples shampoo and detergents $(2,3)$. Several techniques, such as chemical oxidation, biological treatment, coagulation, photocatalytic degradation and adsorption, have been explored to remove the contaminants from wastewater. The most reliable and effective method for removal of pollutants is adsorption technique. Many kinds of adsorbents have been reported, such as zeolites, activated carbons, agricultural by-products, clays, biomass and polymeric materials as hydrogels (4). 
In recent years a great deal of interest has been observed in relation to the applicability of the polymers for removal separation and purification of pollutants from contaminated water. The water holding capacity of the hydrogels arise mainly due to the presence of hydrophilic groups, amino, carboxyl and hydroxyl groups, in the polymer chains. The water holding capacity of the hydrogel is dependent on the number of the hydrophilic groups and crosslinking density.

Polyacrylamide is highly water-absorbent, forming a soft gel when hydrated, used in such applications as in materials with electrolyte properties based on the ionized amide groups. Polyacrylamide P(AAm) hydrogels and their derivatives were the subject of many studies. P(AAm) hydrogels containing a hydrophilic group has been used for the adsorption of some heavy metal ions, (5) anions and basic dyes, $(6,7)$.

\section{Materials And Methods}

\section{Materials}

Epichlorohydrin (EPI) and Acrylamide (AAm) were received from Merck, (Germany) with 99\% purity and were used without further purification.

\section{Apparatus and methods}

\section{Preparation of hydrogels}

The poly (Acrylamide /Epichlorohdrin) hydrogels of acrylamide content 20 (\%) and epiclorohydrin 1.26 $x 10^{-3} \mathrm{~mol} / \mathrm{g}$ acrylamide were prepared at different irradiation dose. The prepared solutions were placed in glass test tubes and gamma irradiated for $(5,10,15,20,25,30$ and 35$) \mathrm{kGy}$ using $\mathrm{Co}^{60}$ gamma source. Also the poly (Acrylamide /Epichlorohdrin) hydrogels at different AAm and epi content were prepared.

\section{Gamma radiation source:}

The samples were irradiated with $\mathrm{Co}^{60}$ Indian research irradiator gamma chamber with activity 9100 curies which is modified to a dose rate ranging from 0.99 to $0.85 \mathrm{~Gy} / \mathrm{sec}$. The irradiation chamber was constructed by the National Center for Radiation Research and Technology (NCRRT), Atomic Energy Authority of Egypt (AEAE).

\section{Gelation procedure:}

The prepared hydrogels obtained in cylindrical shapes were cut into 2-3 mm, dried and weighted $\left(\mathrm{W}_{\mathrm{i}}\right)$. Then, the hydrogels were extracted in deionized water for 6 hours at $80^{\circ} \mathrm{C}$, and were occasionally shaken. The insoluble part corresponding to the cross-linked sample was dried and weighed $\left(\mathrm{W}_{\mathrm{d}}\right)$. The gelation \% was calculated by the following equation:

Gel $(\mathbb{\nabla})=\left(\mathrm{W}_{\mathrm{d}} / \mathrm{W}_{\mathrm{i}}\right) \times 100$ 
Where $W_{i}$ is the weight of dried hydrogel before extraction and $W_{d}$ is the cross-linked weight of samples after the extraction of residual homopolymer and monomer.

\section{Swelling studies and diffusion characteristics evaluation of the hydrogels:}

To study the swelling properties of $\mathrm{P}$ (AAm/Epi) hydrogels, a pre-weighed cylindrical shaped hydrogels were soaked in $50 \mathrm{ml}$ of distilled water then weighted at different time intervals to a constant weight. At every measurement, the excess water on the hydrogel discs was removed superficially by filter paper and then weighted. The swelling (\%) in each case was calculated as follows:

Swelling $(\%)=\left(\mathrm{W}_{\mathrm{s}}-\mathrm{W}_{\mathrm{o}} / \mathrm{W}_{\mathrm{o}}\right) \times 100$

where $W_{0}$ and $W_{s}$ are the weights of the sample in the dry state and swollen state at time $(t)$, respectively (8-10).

\section{Scanning electron microscopy (SEM)}

The swollen freeze dried hydrogels were prepared using freeze dryer (Modulyo Jencons' Scientific Limited, England). A JEOL-JSM-5400 Scanning electron microscope-Japan was used for investigating the pore structure and morphology of different hydrogels. The swollen hydrogel samples were freezedried and coated with gold for SEM observation.

\section{Testing nutrient ions removal by the hydrogel}

A known weight dry hydrogels were soaked in fixed volume of sulphate and phosphate anion solutions with known concentration $\left(\mathrm{C}_{\mathrm{o}}\right)$ for 24 hours. The remaining concentrations after equilibrium $\left(\mathrm{C}_{\mathrm{q}}\right)$ were determined using colorimeter (HACH DR/890, USA).

\section{Sulphate $\left(\mathrm{SO}_{4}^{-2}\right)$ ions determination}

Sulfate ions in the sample react with barium in the SulfaVer 4 Sulfate Reagent to form insoluble barium sulfate. The amount of turbidity formed is proportional to the sulfate concentration. The SulfaVer 4 also contains a stabilizing agent to hold the precipitate in suspension $(11,12)$.

\section{Phosphate $\left(\mathrm{PO}_{4}^{-3}\right)$ ions determination}

The procedure is based on a UV catalyzed oxidation of phosphonate to orthophosphate. Range may be as low as 0 to $2.5 \mathrm{mg} / \mathrm{L}$ or as high as 0 to $125 \mathrm{mg} / \mathrm{L}$. Phosphonate is converted to orthophosphate during the UV digestion. Both the sample and the blank will develop color if orthophosphate is present in the sample. The increase in color in the sample is proportional to the phosphate produced in the digestion. (13)

\subsection{Adsorption capacity}


The adsorption capacity $\mathrm{Q}$, ( $\mathrm{mg} / \mathrm{g}$ hydrogel) was calculated depending on the amount of anions uptake (in $\mathrm{mg}$ ) by unit mass (in $\mathrm{g}$ ) of the hydrogels using the following equation (14):

$\mathrm{Q}=\left(\mathrm{C}_{\mathrm{o}}-\mathrm{C}_{\mathrm{q}}\right) \mathrm{V} / \mathrm{m}$

where, $\mathrm{C}_{\mathrm{o}}$ and $\mathrm{C}_{\mathrm{q}}$ are the initial and the residual concentration of anions at equilibrium, respectively, $\mathrm{m}$ is the weight of hydrogels and $V$ is the volume of the anions solution.

\subsection{Regeneration/ desorption}

Experiments were performed to determine whether the $\mathrm{P}$ (AAm/Epi) hydrogels could be regenerated after having bound the anions from wastewater. The anion saturated $\mathrm{P}(\mathrm{AAm} / \mathrm{Epi})$ hydrogel was treated with 50 $\mathrm{ml}$ of $1 \mathrm{~N} \mathrm{NaOH}$ solution for 24 hours after the anion removal experiment in wastewater. The hydrogel was removed from the waste solution consisting of $\mathrm{Na}_{2} \mathrm{SO}_{4}$ and $\mathrm{Na}_{3} \mathrm{PO}_{4}$ that were formed during the treatment. The hydrogel was re-washed with deionized water to remove any residual $\mathrm{Na}_{2} \mathrm{SO}_{4}$ and $\mathrm{Na}_{3} \mathrm{PO}_{4}$ that remained. The hydrogel was then dried in an oven to prepare it for reuse in a new anion removal experiment. (15)

\section{Results And Discussion}

\section{Characterization of the prepared hydrogels}

\section{Effect of irradiation dose on gelation percent}

Figure (1) shows the effect of different irradiation dose on gelation percent at acrylamide content $20 \%$ and Epi equal $1.26 \times 10^{-3} \mathrm{~mol} / \mathrm{g}$ acrylamide. When $\mathrm{P}$ (AAm/ Epi) was prepared by different gamma irradiation doses from 5 to $35 \mathrm{kGy}$, gelation percent increased from $88.87 \%$ to $93.18 \%$ by increasing the irradiation dose from $5 \mathrm{kGy}$ reaching maximum at $25 \mathrm{kGy}$ then level off at $35 \mathrm{kGy}$.

These results may be attributed to the increase in the available free radical concentration and higher degree of crosslinking of the hydrogel structure during copolymerization process by irradiation (16). This may be also due to; at low dose, the network consists of polymer chains jointed through multifunctional junctions with no or very few closed cycles, thus forming giant molecules with branches and entanglements. When the radiation dose was increased beyond a certain value, the polymer chains would be crosslinked and a gel is then obtained (17). The leveling off of gelation (\%) of P (AAm/ Epi) hydrogel can be attributed to the degradation of the hydrogel by the effect of irradiation dose. It is known that the gelation percent increases with the irradiation dose, but in such case, the rate of radiation degradation may be equal to the rate of radiation crosslinking, as a result the gelation levels off as irradiation dose increases (18).

\section{Effect of irradiation dose on swelling percent}


The influence of swelling time on the swelling percent for $\mathrm{P}(\mathrm{AAm} / \mathrm{Epi})$ hydrogels prepared at different irradiation doses is shown in Figure (2). It can be seen that, for all the investigated samples, the water absorbency of the hydrogels highly increased as the swelling time increased. The results show that the swelling percent of all hydrogels reached more than $500 \%$ within $5 \mathrm{~h}$ only. On the other hand, the swelling of the hydrogels decreased as the radiation dose increased. It was reported that the increase in the total irradiation dose increases the concentration of free radicals generated from acrylamide molecules and the crosslinking capability of the AAm molecules. Such increment in the degree of crosslinking reduces the free volume available for swelling by increasing the tightness of the network structure that hinders the relaxation of the polymer chains and the mobility of the swelling medium, consequently it lowers the hydrogel swelling (19).

\subsubsection{Kinetics Study}

\section{Swelling/Diffusion mechanism}

Absorption of water from the environment into the hydrogels system, changes the dimensions and physicochemical properties of the system. The diffusion of water into the hydrogels was classified into three different types based on the relative rates of diffusion and polymer relaxation (20). These classifications of the diffusion of water into the hydrogels are:

\section{i- Case I or Fickian Diffusion}

Case I or Fickian diffusion occurs when the rate of diffusion is much less than that of relaxation. When the hydrogels swells in the water, the swollen gel follows Fick's law. Thus, the rate of swelling by Case I systems is dependent on $t^{1 / 2}$ and the diffusion constant $n=0.5$.

\section{ii- Case II Diffusion}

Case II diffusion (relaxation-controlled transport) occurs when diffusion is very rapid compared with the relaxation process. In Case II systems, diffusion of water through the gel is rapid compared with the relaxation of polymer chains. Thus, the rate of water penetration is controlled by the polymer relaxation $(n=1)$.

\section{iii- Non-Fickian or Anomalous Diffusion}

Non-Fickian or anomalous diffusion occurs when the diffusion and relaxation rates are comparable. Swelling depends on two simultaneous rate processes, water migration into the hydrogel and the relaxation of polymer chains $(0.5<n<1)$.

The swelling/diffusion kinetic parameters, as diffusion coefficients (D), swelling constant (k), diffusion constant ( $\mathrm{n}$ ) at maximum equilibrium swelling were calculated using the dynamic swelling values for $P(A A m /$ Epi) hydrogels by equation $(4):(21,22)$. 
In the above equation, $\mathrm{F}$ are fraction of swelling percent due to the water uptake, $\mathrm{M}_{\mathrm{t}}$ is the adsorbed water at time $t$ and $M_{\infty}$ is the adsorbed water at equilibrium, $k$ is the swelling constant, and $n$ is the diffusion constant. This equation was applied to the initial stages of swelling of $\mathrm{P}(\mathrm{AAm} / \mathrm{EPI})$ at different $A A m$ contents and irradiation doses. The plots of $(\operatorname{In} F)$ versus $(\ln t)$; where $t$ is the time of swelling, are shown in Figures (5and 6).

The values of the exponent $(n)$ and swelling constant $(k)$ were calculated from the slope and intercept of the lines, respectively. The values are presented in Table (1) as a function of different irradiation dose. Diffusion constant values of these hydrogels indicate that the water penetration is by non-Fickian transport mechanism because diffusion constant $(n)(0.5315-0.6998)$ values had fallen between 0.5 and 1.0 Table (1). It was reported that the non-fickian or anomalous diffusion mechanism where $0.5<\mathrm{n}<1$ indicates that the diffusion and relaxation rates are comparable Ritger et al., (1987) (21). The entrance of water molecules into the polymer follows non-Fickian and depends on two simultaneous rate processes, water migration into the hydrogel and the relaxation of polymer chains. The diffusion coefficient (D) of cylindrical polymer was calculated from equation $(6)(22,23)$.

\section{$F=4\left(D t / \pi r^{2}\right)^{1 / 2}$}

Here (D) is the apparent diffusion coefficient for the transport of the penetrate (water) into the hydrogel, $(t)$ is the swelling time $(h)$ in hours, and $(r)$ is the radius of the cylindrical polymer sample. For hydrogels, the graphs of swelling ratio versus $t_{1 / 2}$ are plotted and are shown in Figures ( 3 and 4 ). The linearity obtained in the first stage of the process corresponds to the values of the swelling ratio. The apparent diffusion coefficient (D) can be calculated from the slope of the straight line (24). The values of the diffusion coefficient of $\mathrm{P}$ (AAm/Epi) hydrogel are listed in Tables (1). It can be noticed that, the correlation coefficient $\left(R^{2}\right)$ for all investigated hydrogels ranges from 0.984 to 0.991 indicating a better fitting of the experimental data.

\section{Scanning electron microscopy of the produced hydrogel}

The shape, surface morphology, and porosity of P (AAm/ Epi) hydrogel at different Epi content have been examined by SEM as (Figure 5). From the figure it can be noticed that, the increase of Epi content leads to their accumulation on the pores of the hydrogel Further, increase of Epi content in the hydrogels was not only observed on the surface but also within the holes of the hydrogel pores $(25,26)$.

\section{Adsorption study of P (AAm/ Epi) hydrogels}

\section{Evaluation of equilibrium adsorption isotherm}

Adsorption is one of the most common methods used in wastewater treatment. The main advantages of adsorption are; high efficiency, good selectivity, moderately high removal performance, cost-effectiveness 
and easy regeneration process of adsorbents. Isotherms studies can describe how the adsorbates interact with adsorbents, affording the most important parameter for designing a desired adsorption system. The adsorption isotherms of sulphate and phosphate ions on all investigated hydrogels as a function of acrylamid contents are shown in Figures ( 6 and 7). From the figures it can be clearly noticed that, the adsorption isotherms indicate that the adsorption capacity of the investigated anions into the hydrogels decreases with increasing the acrylamide content. The obtained results may be attributed to the high crosslinking of the hydrogels obtained at high monomer content which lead to decreasing the diffusion of the anions effluents into the hydrogels (27-29).

Figures ( 6 and 7$)$ also indicate that, the adsorption capacity of the investigated anions into the hydrogels decreases with increasing the Epi content from $1.26 \times 10^{-3} \mathrm{~mol} / \mathrm{g}$ AAm to Epi $1.56 \times 10^{-3} \mathrm{~mol} / \mathrm{g}$ AAm then to Epi $1.86 \times 10^{-3} \mathrm{~mol} / \mathrm{g}$ AAm. The observed decrease of the adsorption capacity by increasing the Epi contents may be due to the increase of the crosslinking which increases the tightness of the network structure that hinders the diffusion and mobility of the anions into the hydrogels $(30,31)$. From Figures $(6$ and 7), it can be noted that, the adsorption capacity of sulphate anion onto hydrogels with different Epi content was higher than that of phosphate anion, where the adsorption capacity order is $\mathrm{SO}_{4}{ }^{2-}>\mathrm{PO}_{4}{ }^{-3}$.

\section{Determination of the removal percentages of the tested nutrients}

The evaluation of the removal percent of sulphate and phosphate by P (AAm/Epi) hydrogels at different AAm and Epi content are listed in Table (2) according to equation .

\section{Removal (\%) $=[(\mathrm{Co}-\mathrm{Ce}) / \mathrm{Co}] \times 100$}

Where $\mathrm{Co}$ and $\mathrm{Ce}$ are the initial and equilibrium anions concentration $(\mathrm{mg} / \mathrm{l})$, respectively. From the table it can be noticed that the removal percentage of sulphate and phosphate increased by decreasing AAm content and it showed also that, the removal percentage decreased by increasing Epi content from $1.26 \times 10^{-3}$ to $1.86 \times 10^{-3}$. These finding may be attributed to the high crosslinking obtained by increasing AAm and Epi contents. In comparison, it was found that, the removal percentage of sulphate ions is more than that of phosphte ions (32).

In a comparison, the maximum adsorption capacity of sulphate ions using barium-modified blast-furnace slag geopolymer (Ba-BFS-GP) was up to $119 \mathrm{mg} / \mathrm{g}$ (32) and that using modified rice straw was up to $74.76 \mathrm{mg} / \mathrm{g}$ (33). In this work the maximum adsorption capacity of sulphate ions using $\mathrm{p}(\mathrm{AAm} / \mathrm{Epi})$ hydrogels was up to $220 \mathrm{mg} / \mathrm{g}$.

\section{Freundlich isotherm study}

The adsorption isotherms of sulphate, phosphate, nitrate and nitrite ions are shown in Figures (8 and 9). The adsorption isotherms indicate that the adsorption capacity for all investigated anions are clearly affected by the acrylamide content. The isotherm data were analyzed by Freundlich equation, where the 
Freundlich model is employed to describe heterogeneity. The equilibrium isotherm results were found to be best fitted by Freundlich isotherm model (33).

\section{$\log q e=\log k_{f}+1 / n \log C e$}

where qe is $\mathrm{mg}$ adsorbate per gram of dry adsorbent, Ce is the equilibrium anion concentration $(\mathrm{mg} / \mathrm{l})$, and the Freundlish empirical constants $\mathrm{k}_{\mathrm{f}}$ and $\mathrm{n}$ referred to the ability of polymer adsorbent and affinity of adsorbat solution, respectively.

The Freundlich isotherm constants and $\mathrm{R}^{2}$ values for different anion solutions are given in Table (3). The experimental data show a better fitting $\left(R^{2}>0.9\right)$ to the Freundlich model for all anions. From Table (3) it can be noticed that $1 / \mathrm{n}$ values indicate that the adsorption process of sulphate is chemical, while that of phosphate anion is physical. On contrary, $1 / \mathrm{n}$ values of sulphate anion is nearly close to unity, so the adsorption process is linear $(34,35)$.

\section{Regeneration process}

\section{Desorption and reusability of P (AAm/ Epi) hydrogels}

Desorption process using the same $\mathrm{P}$ (AAm/ Epi) hydrogel was carried out as mentioned in the experimental section. The procedure describes "regeneration cycle" that involves an anions adsorbents experiment followed by a release experiment and a second removal experiment. The adsorption capacity of sulphate and phosphate anions after regeneration were evaluated and represented in figures (10 and 11). The figures showed that, the adsorption capacity of $P$ (AAm/ Epi) hydrogels toward different anions are clearly affected by the acrylamide and Epi contents, where the adsorption capacity was found to decrease as the acrylamide content increases. It can also be noticed that, the adsorption capacity are in the same manner but with lower values than before regeneration which indicated that the hydrogel keep its characteristic without any deformation (15-36).

\section{Removal percentages after the regeneration process}

Table (4) shows the removal precent of sulphate and phosphate ions with P (AAm/ Epi) hydrogels at different acrylamide and Epichlorohydrin contents after regeneration. The calculated removal percentages were found to increase by decreasing the AAm and Epi contents. The removal percent of sulphate by $\mathrm{P}$ (AAm/ Epi) hydrogels was higher than that of other anions (32 -37).

\subsubsection{Freundlich isotherm study after the regeneration process}

The adsorption isotherms for the different anions tested are shown in Figures (12 and 13) The adsorption isotherms indicated that the adsorption capacity for all investigated anions are clearly affected by the acrylamide contents. The isotherm data were analyzed by Freundlich equation, where the Freundlich model was employed to describe heterogeneous. (32). 
The Freundlich isotherm constants ( $n$ and $k$ ) and $R^{2}$ values for different anion solutions are listed in Table (5). The experimental data shows fitting of over $a \mathrm{R}^{2}$ of 0.82 to the Freundlich model for all anions. The higher values of $1 / \mathrm{n}$ (Table 5 ) indicate that the adsorption process of all anions are physical. These results may be attributed to the high crosslinking process that may lead to the formation to more dense and sound network structure, which would hinder the release of anions from the hydrogels into the effluent medium during the regeneration process (31-33).

\subsubsection{The regeneration efficiency}

The regeneration efficiency percent has been calculated to evaluate the removal (\%) after regeneration process comparing with that before regeneration. The regeneration efficiency (\%) can be calculated by the following equation:

\section{Regeneration efficiency $(\%)=($ Removal $(\%)$ after regeneration $/$ Removal $(\%)$}

\section{before regeneration) $\times 100$}

Table (6) shows results of sulphate and phosphate ions removal with P (AAm/ Epi) hydrogels at different AAm and Epi contents. From the table it can be noticed that, the removal of sulphate and phosphate ions is slightly affected by the AAm and Epi contents (32).

The calculated regeneration efficiency (\%) values found to be ranged between $63.2(\%)$ and $46(\%)$. The relatively higher regeneration efficiency (\%) and keeping the hydrogels its shape without any deformation promising to use the same hydrogels further times which decrease the economic cost.

\section{References}

1. Wang, Y., Gao, B.Y., Yue, W.W., Yue, Q.Y., (2007). Adsorption kinetics of nitrate from aqueous solutions onto modified wheat residue. Colloids Surfaces. vol 308, 1-5.

2. Davis.N.G., Horecka.J.L. , Sprague.G.F. (1993), Cis- and trans-acting functions required for endocytosis of the yeast pheromone receptors. The J. of Cell Biology. 122:53-65.

3. Sauthier, N., Gasmick, A.,Blancheton,J.P.,(1998). BIOLOGICAL DENITRIFICATION APPLIED TO A MARINE CLOSED AQUACULTURE SYSTEM Water Reserch. 32:1932-1938.

4. Zhang Y., Shen S., Wang S., Huang J., Su P., Wang Q. and Zhao B.,(2014). Chemical engineering journal, 239, 250.

5. Saraydın.D, Karadag `.E, Gu“ven.O, Sci.S. Technol. 1996, 31, 2359.

6. Saraydın.D, Karadag `.E , Gu“ven. O, Sci.S. Technol. 1995, 30, 329.

7. El-Arnaouty.M.B. (2010) Radiation synthesis and characterization study of imprinted hydrogels for metal ions adsorption. Polymer-Plastics Technology and Engineering, 49, 963-971.

8. Korsmeyer R. W., Peppas N. A., Roseman T. J. and Mansdorf S. Z., (1983).Controlled Release Delivery Systems, (Eds.), Marcel Dekker, NewYork, p. 77. 
9. Olpan D. S, Duran S. and Torun M.(2008). Removal of cationic dyes by poly(acrylamide-co-acrylic acid) hydrogels in aqueous solutions, Radiation Physics and Chemistry, 77: 447-452 .

10. Rosiak J.M. and Ulanski P.,(1999) Synthesis of hydrogels by irradiation of polymers in aqueous solution . Radiation Physics and Chemistry 55:139-151.

11. Kolthoff, I.M. Meehan, E.J. Sandell, E.B. Bruckenstein, S. (1969). Quantitative Chemical Analysis, 4th ed. Macmillan Co., New York, N.Y.

12. APHA, AWWA and WEF (2000) Standard Methods for the Examination of Water and Wastewater; 21st Edition.

13. Blystone, P.; Larson, P. (1981) A Rapid Method for Analysis of Phosphate compounds, International Water Conference, Pittsburgh, USA.

14. Sabova L., Chmielewska E., Gaplovska K.,(2010) Development and exploitation of combined zeolite adsorbents for removing oxyanions from water, Chem. Listy $104: 243-250$.

15. Kioussis D. R. , Wheaton F. W., Kofinas. P. (2000) Reactive nitrogen and phosphorus removal from aquaculture wastewater effluents using polymer hydrogels. Aquacultural Engineering 23:315-332.

16. Eid, M. El-Arnaouty, M. B. Salah, M. Soliman, E. Hegazy, E. A. (2012) Radiation synthesis and characterization of poly(vinyl alcohol)/poly(N-vinyl-2-pyrrolidone) based hydrogels containing silver nanoparticles. J. Polym. Res. 19:9835.

17. Saraydin, D., Oztop, H. N., Karadag, E., Oztop, A. Y., Isikver, Y. Guven, O. (2002) The use of immobilized Saccharomyces cerevisiae on radiation crosslinked acrylamide-maleic acid hydrogel carriers for production of ethyl alcohol process. Biochemistry, 37, 1351.

18. Eid.M (2008). In vitro release studies of vitamin $B_{12}$ from poly $\mathrm{N}$-vinyl pyrrolidone/starch hydrogels grafted with acrylic acid synthesized by gamma radiation. Nuclear Instruments and Methods in Physics Research B 266 : 5020-5026.

19. Murthy, P.S. K., Mohan, Y. M., Sreeramulu, K.J., and Raju, K. M., Semi-IPNs of starch and poly(acrylamide-co-sodium methacrylate): Preparation, swelling and diffusion characteristics evaluation Reactive \& Functional Polymers 66 (2006) 1482-1493

20. Erdener Karadag Omer Barıs,Uzüm, Dursun Saraydin, Olgun Güven, Dynamic swelling behavior of gradiation induced polyelectrolyte poly (AAm-Co-CA) hydrogels in urea solutions. International Journal of Pharmaceutics 301 (2005) 102-111

21. Ritger, P.L., Peppas, N.A., (1987). A Simple equation for description of solute release. I. Fickian and non-Fickian release from swellable devices. J. Contr. Release 5, 37-42.

22. Mohan, Y. M., Premkumar. T., Joseph. D. K. and Geckeler, K. E. (2007) Stimuli-responsivepoly (Nisopropylacrylamide-co-sodium acrylate) hydrogels: A swelling study in surfactant and polymer solutions. Reactive and Functional Polymers, 67- 844.

23. Miller-Chou, B.A., and Koeing, J.L. (2003) A review of polymer dissolution. Prog. Polym. Sci. 28:12231270. 
24. Siepmann, J., Kranz, H., Bodmeier, R., and Peppas, N.A. (1999) HPMC matrices for controlled drug delivery; a new model combining diffusion, swelling, and dissolution mechanisms and predicting the release kinetics. Pharm Res 16 (11): 1748-56.

25. El-Arnaouty. M. B., Eid. M., Atia. K. S., Dessouki. A. M.(2009). Characterization and Application of Grafted Polypropylene and Polystyrene Treated with Epichlorohydrin Coupled with Cellulose or Starch for Immobilization Processes. Journal of Applied Polymer Science, 112, 629-638

26. Eid M. and El-Arnaouty M. B.(2009) Kinetic Degradation and Controlled Drug Delivery System Studies for Sensitive Hydrogels Prepared by Gamma Irradiation, Journal of Applied Polymer Science, 1121745 .

27. M. B. El-Arnaouty, M. Eid, and A. M. Abdel Ghaffar. (2015) Radiation Synthesis of Stimuli Responsive Micro-porous Hydrogels for Controlled Drug Release of Aspirin. Polymer-Plastics Technology and Engineering, 54: 1215-1222.

28. El Bouraie. M, Masoud A. A.(2017) Adsorption of phosphate ions from aqueous solution by modified bentonite with magnesium hydroxide $\mathrm{Mg}(\mathrm{OH}) 2$. Applied Clay Science, Volume 140 ,Pages 157-164.

29. Gueu, S. Yao, B., Adouby, K., and Ado, G. (2007) Kinetics and thermodynamics study of lead adsorption on to activated carbons from coconut and seed hull of the palm tree. Int. j. Environ. Sci. tech. 4 (1):11-17.

30. Sen, T.K., Dustin, G., (2011). Adsorption of zinc $(Z n+2)$ from aqueous solution on natural bentonite. Desalination 267, 286-294.

31. Liang .H , Liu .K, Yonghao Ni . (2016) Synthesis of mesoporous a- $\mathrm{Fe}_{2} \mathrm{O}_{3}$ using cellulose nanocrystals as template and its use for the removal of phosphate from wastewater .Journal of the Taiwan Institute of Chemical Engineers 1-6.

32. Runtti .H, Luukkonen .T, Niskanen .M, Tuomikoski .S, Kangas .T, Tynjälä .P, Tolonen .E.T, Sarkkinen .M, Kemppainen .K, Rämö .J, Lassi .U.(2016). Sulphate removal over barium-modified blast-furnace-slag geopolymer. Journal of Hazardous Materials, Volume 317Pages 373-384.

33. Cao .W, Dang .Z, Zhou X.Q, Yi X.Y, Wu P.X, Zhu N.W, Lu G.N(2011).Removal of sulphate from aqueous solution using modified rice straw: Preparation, characterization and adsorption performance. Carbohydrate Polymers, Volume 85, Pages 571-577

34. Bekele.W, Faye .G and Fernandez .N, (2014) Removal of nitrate ions from aqueous solution by modified Ethiopian bentonite clay. International journal of research in pharmacy and chemistry. 4,192-201.

35. Chitrakar .R., Tezuka S., Manikandan .M , Ramachandran .D., Hasan. N, Jeevanandam.M.,Gopal.J, Chun.S (2017). Unprecedented nitrate adsorption efficiency of carbon-silicon nano composites prepared from bamboo leaves. Materials Chemistry and Physics, Volume 189: 12-21

36. Chitrakar. R, Tezuka.S, Sonoda.A, Sakane.K, Ooi.K, Hirotsu.T, (2006). Phosphate adsorption on synthetic goethite and akaganeite, J. Colloid Interface Sci. 298 : 602-608.

37. Zeng .L,. Li .X.M, Liu J.D., (2004) Adsorptive removal of phosphate. From aqueous solutions using iron oxide tailings, Water Res. $38: 1318-1326$. 


\section{Tables}

Table (1): Diffusion parameters of $\mathrm{P}$ (AAm/Epi) hydrogel at acrylamide content $20 \%$ and Epi $1.26 \times 10$ $3 \mathrm{~mol} / \mathrm{g}$ AAm.

\begin{tabular}{|llllll|}
\hline Dose (kGy) & $K$ & $N$ & $L n(F) \& L(t)$ & $D$ & $F \& t^{1 / 2}$ \\
& & & $R^{2}$ & & $R^{2}$ \\
5 & -2.508 & 0.6998 & 0.989 & 0.201 & 0.984 \\
15 & -1.822 & 0.532 & 0.992 & 0.225 & 0.987 \\
25 & -1.634 & 0.5497 & 0.989 & 0.287 & 0.989 \\
35 & -1.576 & 0.5315 & 0.993 & 0.303 & 0.991 \\
\hline
\end{tabular}

Table (2): Removal percent of sulphate and phosphate ions with P (AAm/ Epi) hydrogels at different acrylamide and Epichlorohydrin contents.

\begin{tabular}{|llll|}
\hline AAm contents & Epi content (mol/g AAm) & $\mathrm{SO}_{4}{ }^{2-}$ & $\mathrm{PO}_{4}{ }^{3-}$ \\
\hline 7.5 & & 71.1 & 51.4 \\
10 & $1.26 \times 10^{-3}$ & 61.5 & 36.4 \\
15 & & 39.3 & 28.8 \\
20 & & 29.7 & 19.9 \\
7.5 & & 65.6 & 52.2 \\
10 & $1.56 \times 10^{-3}$ & 56.2 & 39.4 \\
15 & & 34.9 & 23.8 \\
20 & & 25.7 & 15.4 \\
7.5 & & 49.4 & 39.4 \\
10 & $1.86 \times 10^{-3}$ & 38.1 & 34.4 \\
15 & & 23.9 & 24.9 \\
20 & & 16.5 & 18.9 \\
\hline
\end{tabular}


Table (3): Freundlich isotherm constants ( $n$ and $k$ ) and correlation coefficient $\left(R^{2}\right)$ for the adsorption of sulphate and phosphate ions by P (AAm/ Epi) hydrogels at $20 \mathrm{kGy}$.

\begin{tabular}{llllll} 
& Epi content (mol/g AAm) & $1 / \mathrm{n}$ & $\mathrm{n}$ & $\mathrm{k}$ & $\mathrm{R}^{2}$ \\
\hline $\mathbf{S O}_{\mathbf{4}} \mathbf{2 V}^{\mathbf{V}}$ & $1.26 \times 10^{-3}$ & 1.11 & 0.91 & -1.669 & 0.994 \\
& $1.56 \times 10^{-3}$ & 0.99 & 1.01 & -1.298 & 1.00 \\
& $1.86 \times 10^{-3}$ & 0.99 & 1.01 & -1.298 & 1.00 \\
\hline $\mathbf{P O}_{\mathbf{4}}{ }^{3-}$ & $1.26 \times 10^{-3}$ & 1.02 & 0.98 & -1.878 & 0.964 \\
& $1.56 \times 10^{-3}$ & 1.07 & 0.94 & -2.094 & 0.958 \\
& $1.86 \times 10^{-3}$ & 2.78 & 0.36 & -6.373 & 0.967
\end{tabular}

Table (4): Removal percent of sulphate and phosphate ions with P (AAm/Epi) hydrogels at different acrylamide and Epichlorohydrin contents after regeneration.

\begin{tabular}{|c|c|c|c|}
\hline AAm contents & $\begin{array}{l}\text { Epi content } \\
\text { (mol/g AAm) }\end{array}$ & $\mathrm{SO}_{4}^{2} \square$ & $\mathrm{PO}_{4}{ }^{3} \mathrm{\square}$ \\
\hline 7.5 & & 43.7 & 32.5 \\
\hline 10 & $1.26 \times 10^{-3}$ & 34.2 & 21.7 \\
\hline 15 & & 21.3 & 17.1 \\
\hline 20 & & 15.4 & 11.6 \\
\hline 7.5 & & 40.3 & 31.4 \\
\hline 10 & $1.56 \times 10^{-3}$ & 30.5 & 23.3 \\
\hline 15 & & 17.5 & 13.8 \\
\hline 20 & & 11.8 & 8.5 \\
\hline 7.5 & & 30.4 & 24.5 \\
\hline 10 & $1.86 \times 10^{-3}$ & 20.7 & 21.2 \\
\hline 15 & & 12.3 & 13.3 \\
\hline 20 & & 7.9 & 10.3 \\
\hline
\end{tabular}


Table (5): Freundlich isotherm constants ( $n$ and $k$ ) and correlation coefficient $\left(R^{2}\right)$ for the adsorption of sulphate and phosphate ions by $\mathrm{p}$ (AAm/ Epi) hydrogels at $20 \mathrm{kGy}$.

\begin{tabular}{|c|c|c|c|c|c|}
\hline & $\begin{array}{l}\text { Epi content } \\
\text { (mol/g AAm) }\end{array}$ & $1 / \mathrm{n}$ & $\mathrm{N}$ & $\mathrm{K}$ & $\mathrm{R}^{2}$ \\
\hline \multirow[t]{3}{*}{$\mathrm{SO}_{4}^{2} \square$} & $1.26 \times 10^{-3}$ & 8.786 & 0.114 & -1.965 & 0.965 \\
\hline & $1.56 \times 10^{-3}$ & 1.149 & 0.870 & -3.06 & 0.920 \\
\hline & $1.86 \times 10^{-3}$ & 2.255 & 0.443 & -6.030 & 0.839 \\
\hline \multirow[t]{3}{*}{$\mathrm{PO}_{4}{ }^{3} \mathrm{\square}$} & $1.26 \times 10^{-3}$ & 2.423 & 0.413 & -4.213 & 0.864 \\
\hline & $1.56 \times 10^{-3}$ & 1.294 & 0.773 & -2.051 & 0.999 \\
\hline & $1.86 \times 10^{-3}$ & 2.343 & 0.427 & -4.414 & 0.838 \\
\hline
\end{tabular}

Table (6): The regeneration efficiency of $P$ (Amm/Epi) hydrogel at different acrylamide and epicholrohydrin for the removal of sulphate and phosphate ions at $20 \mathrm{kGy}$.

\begin{tabular}{|llll|}
\hline AAm contents & Epi content (mol/g AAm) & $\mathrm{SO}_{4}{ }^{2-}$ & $\mathrm{PO}_{4}{ }^{3-}$ \\
7.5 & & 61.5 & 63.2 \\
10 & $1.26 \times 10^{-3}$ & 55.6 & 59.7 \\
15 & & 54.2 & 59.4 \\
20 & & 51.9 & 58.2 \\
7.5 & & 60.6 & 60.2 \\
10 & $1.56 \times 10^{-3}$ & 54.0 & 59.2 \\
15 & & 50.1 & 57.5 \\
20 & & 46.0 & 55.2 \\
7.5 & & 61.5 & 62.2 \\
10 & $1.86 \times 10^{-3}$ & 54.3 & 61.7 \\
15 & & 51.5 & 53.5 \\
20 & & 48.0 & 51.8 \\
\hline
\end{tabular}


Scheme 1 is available in the Supplementary Files section.

Figures

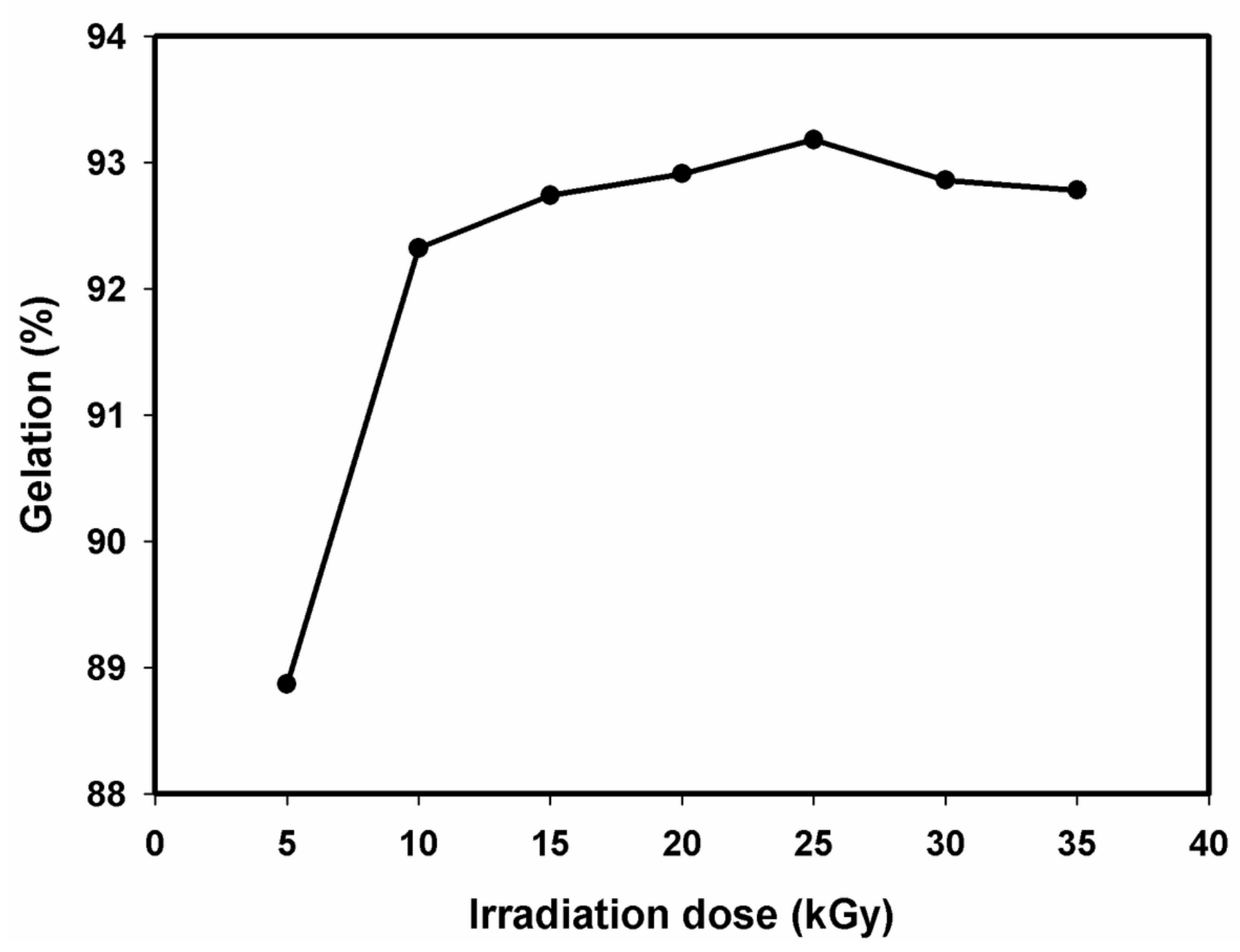

Figure 1

Effect of irradiation dose on gelation percent at acrylamide content $20 \%$ and epiclorohydrin $1.26 \times 10-3$ $\mathrm{mol} / \mathrm{g}$ acrylamide. 


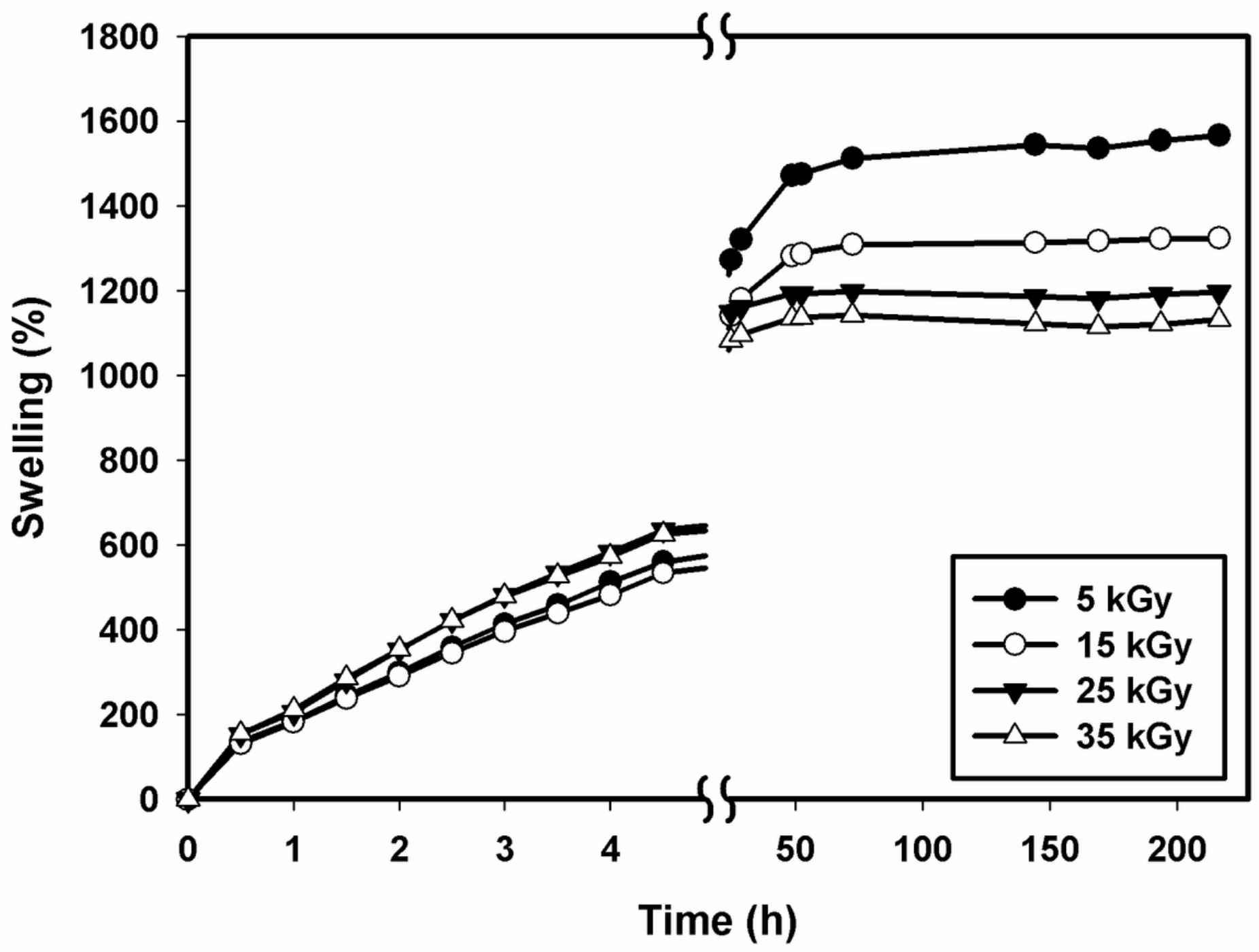

Figure 2

Effect of different irradiation doses on swelling percent at acrylamide content $20 \%$ and Epi $1.26 \times 10-3$ $\mathrm{mol} / \mathrm{g}$ acrylamide. 


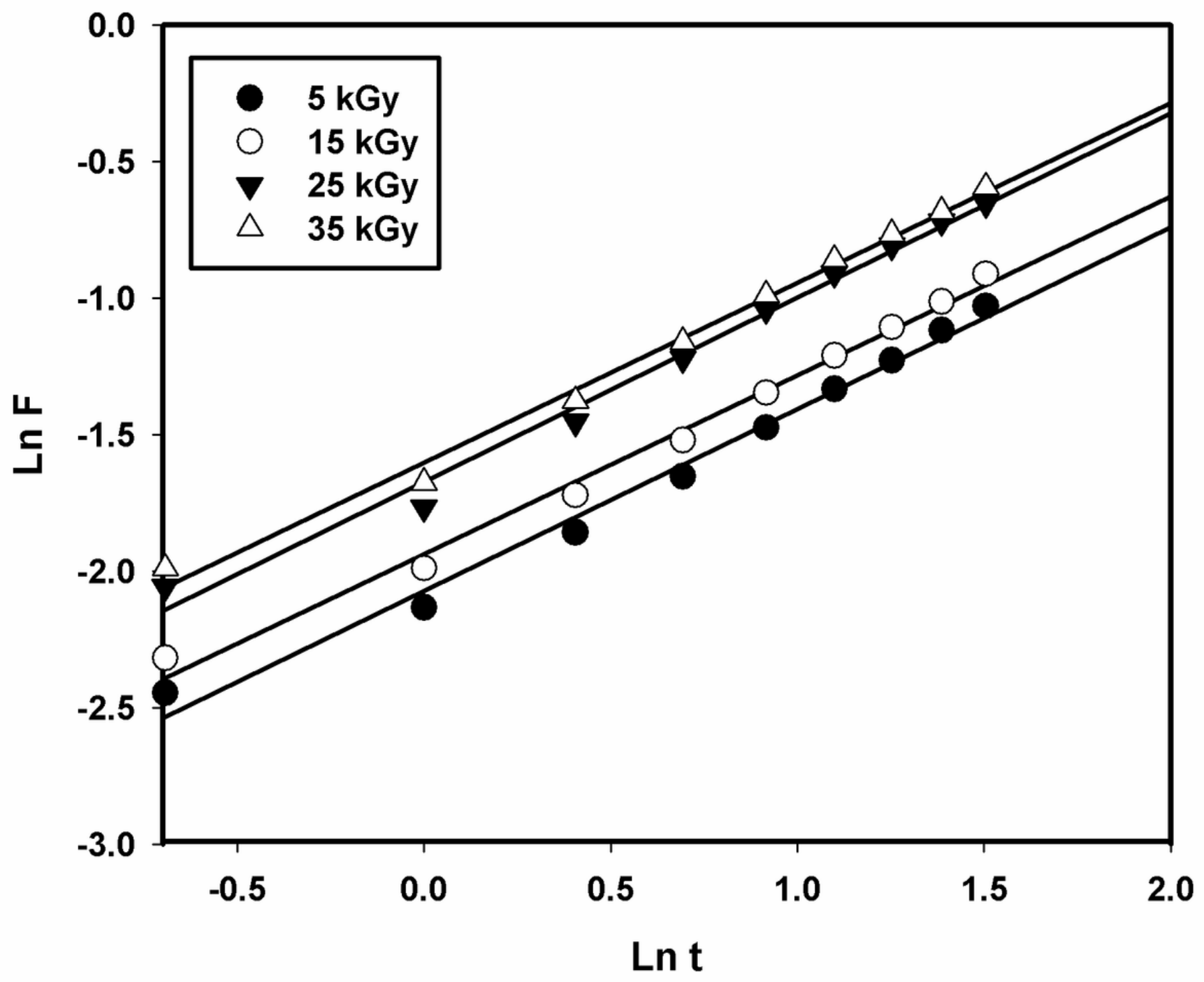

Figure 3

Relationship between In (F) and In (t) at different irradiation doses, (acrylamide content $20 \%$ and epichlorohydrin content $1.26 \times 10-3 \mathrm{~mol} / \mathrm{g}$ acrylamide). 


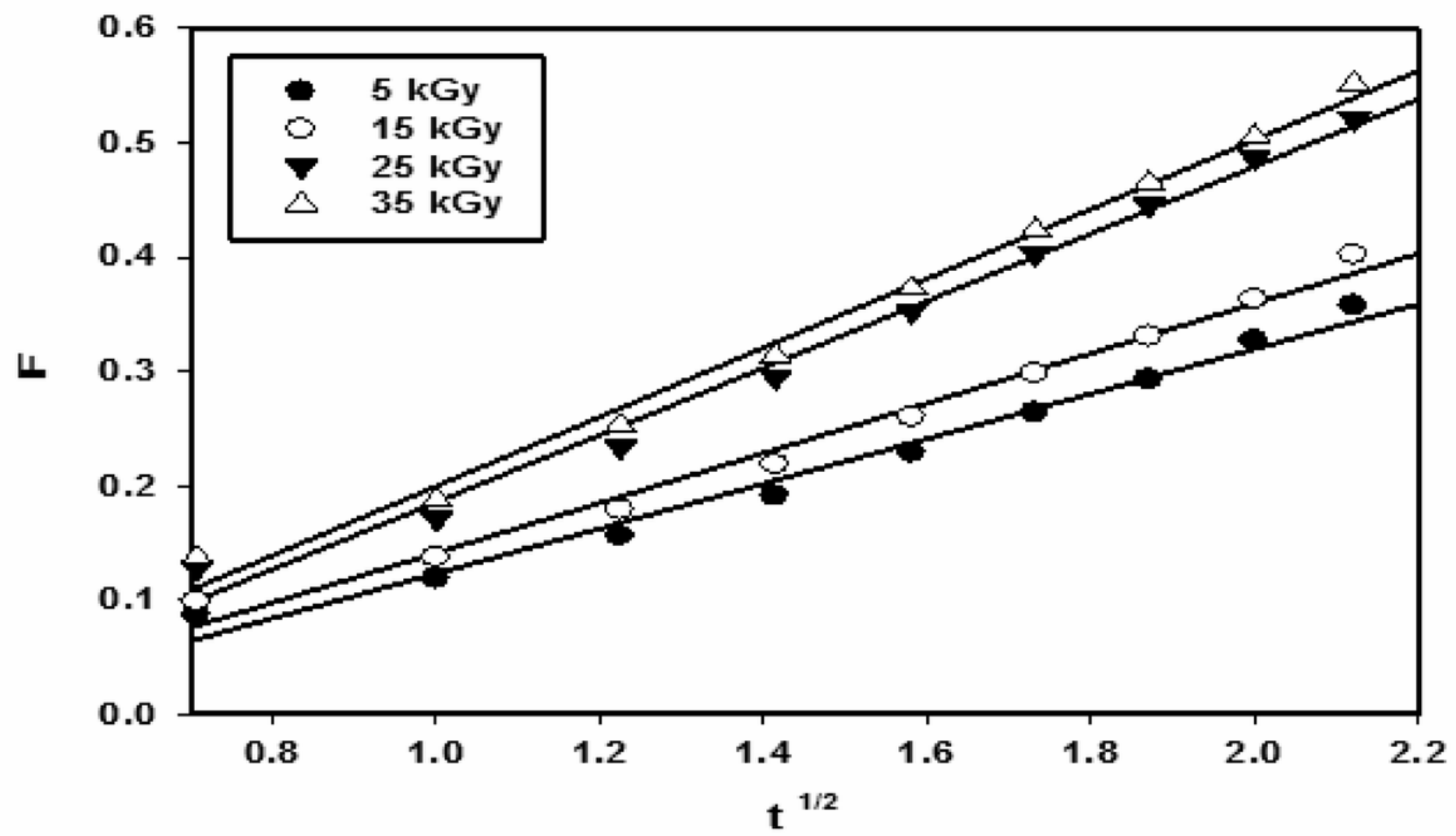

Figure 4

Effect of irradiation dose on the swelling ratio at acrylamide content $20 \%$ and Epi $1.26 \times 10-3 \mathrm{~mol} / \mathrm{g}$ acrylamide.
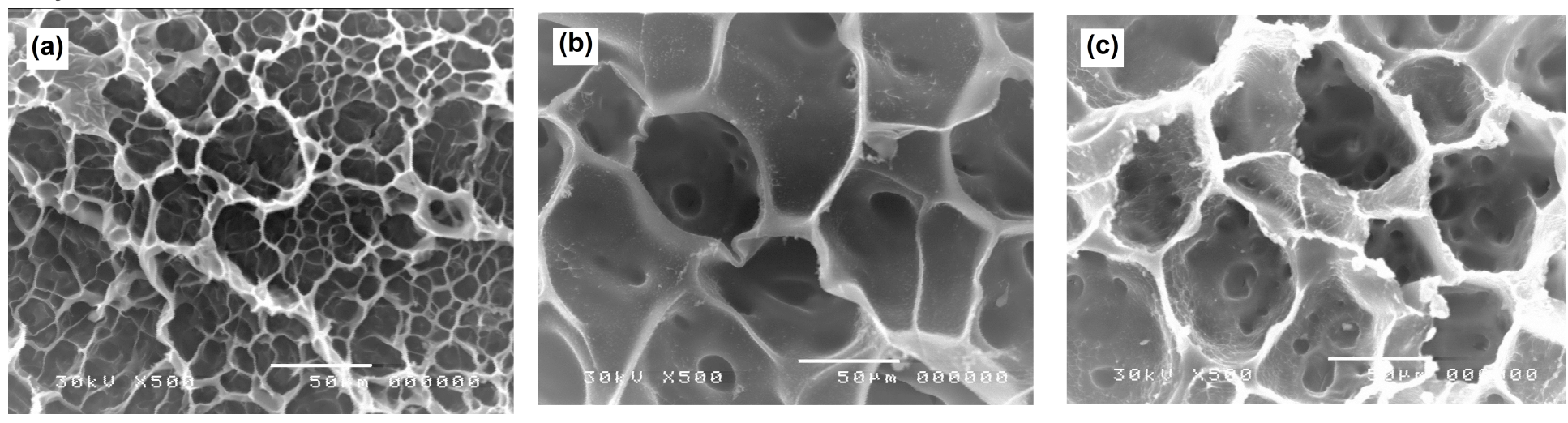

Figure 5

SEM imags of $p$ (AAm/Epi) at different Epi contents, (a) Epi 1.26x10-3 mol/g AAm, (b) Epi 1.56x10-3 $\mathrm{mol} / \mathrm{g}$ AAm and (c) Epi 1.86x10-3 mol/g AAm, irradiation dose $20 \mathrm{kGy}$ and acrylamide $7.5 \%$. 


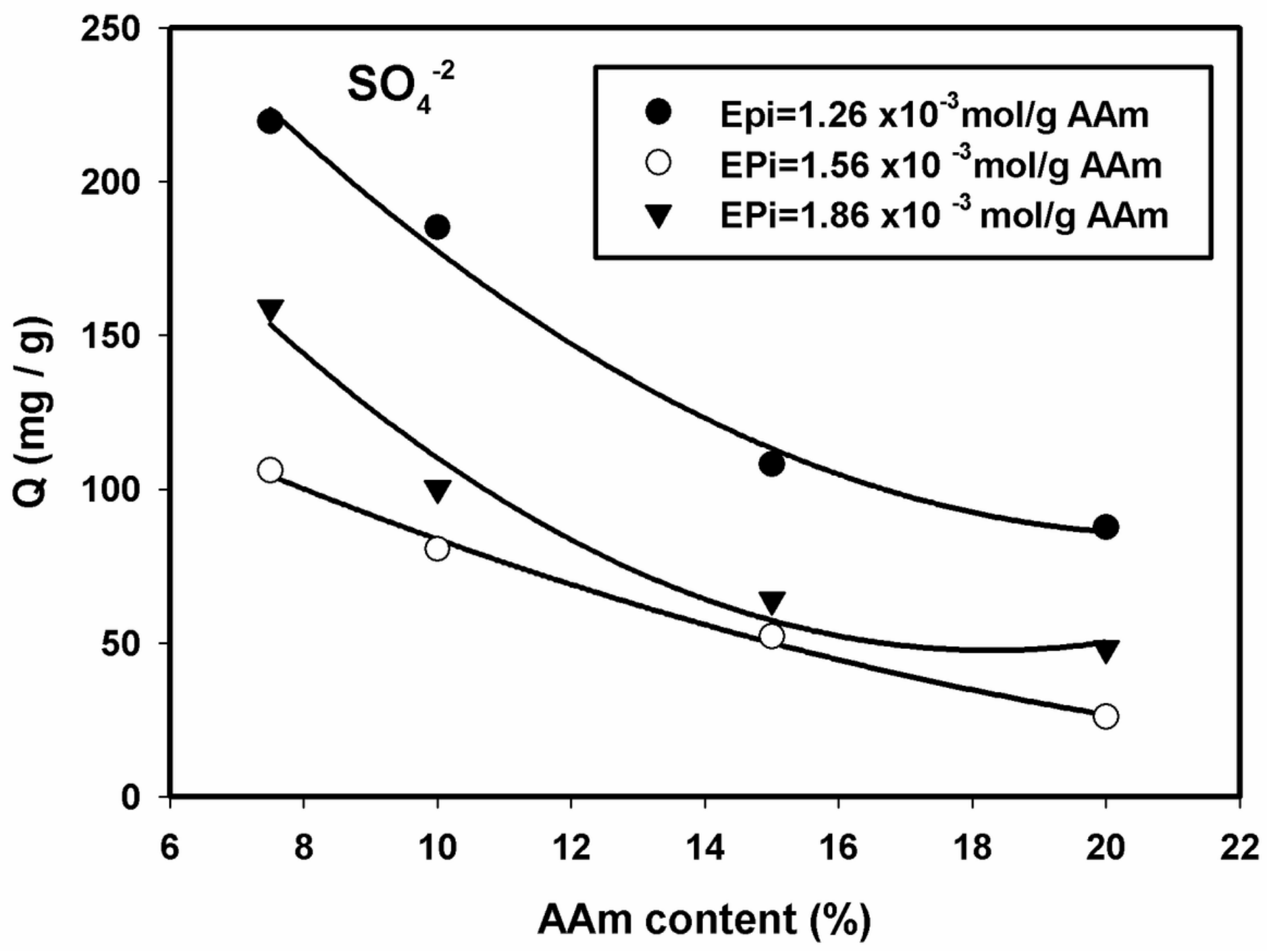

Figure 6

Effect of AAm and Epi content on the adsorption capacity (Q) toward SO4 ions at irradiation dose 20 kGy. 


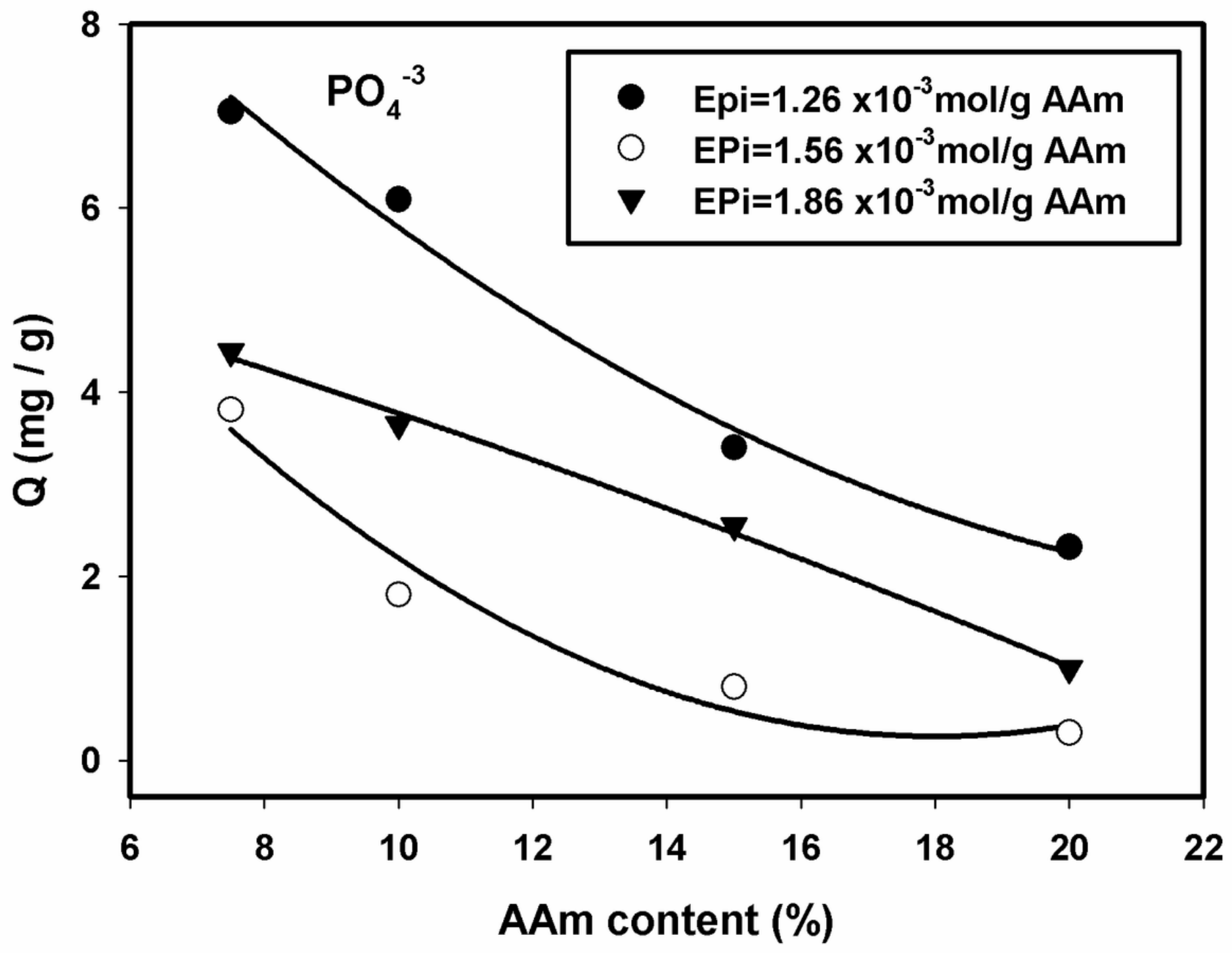

Figure 7

Effect of AAm and Epi content on the adsorption capacity (Q) toward PO4 ions at irradiation dose $20 \mathrm{kGy}$.

Figure 8

Adsorption isotherm of sulphate ions by $\mathrm{P}$ (AAm/Epi) hydrogels at different acrylamide and Epi contents and 20 kGy. 

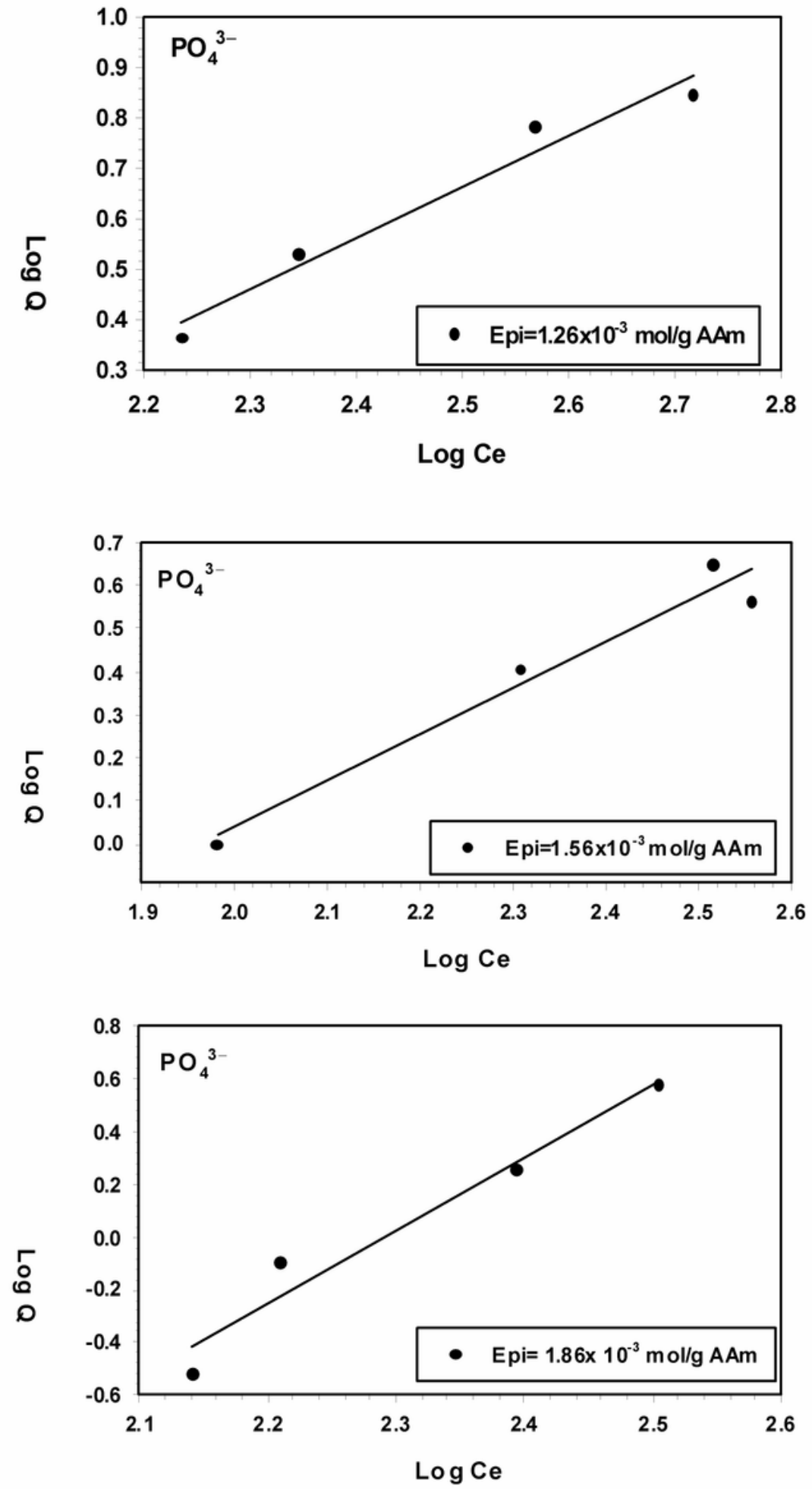

Figure 9

Adsorption isotherm of phosphate ions by $\mathrm{P}(\mathrm{AAm} / \mathrm{Epi})$ hydrogels at different acrylamide and Epi contents and $20 \mathrm{kGy}$. 


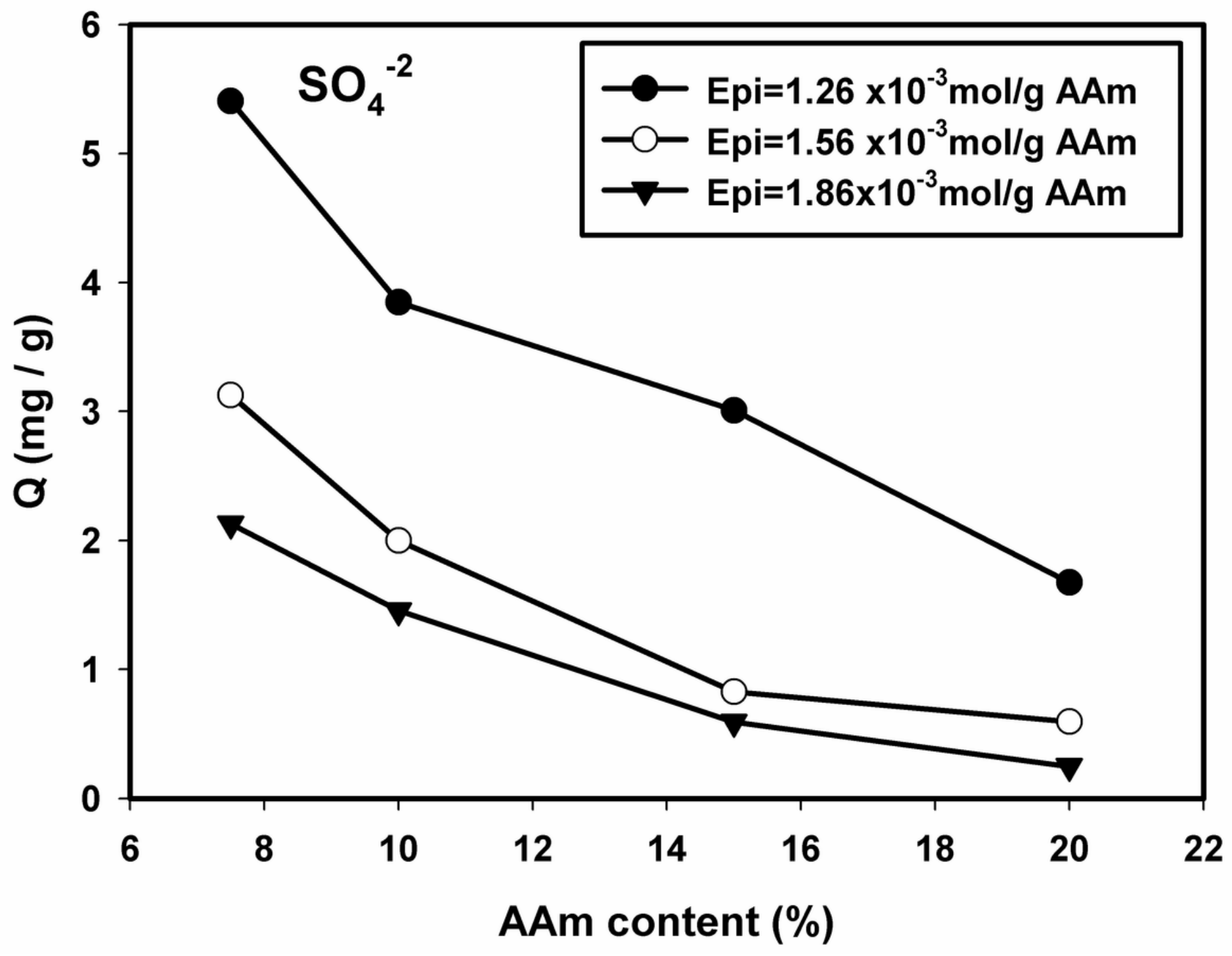

Figure 10

Effect of AAm and Epi contents on the adsorption capacity (Q) toward SO4 ions at irradiation dose 20 kGy after regeneration. 


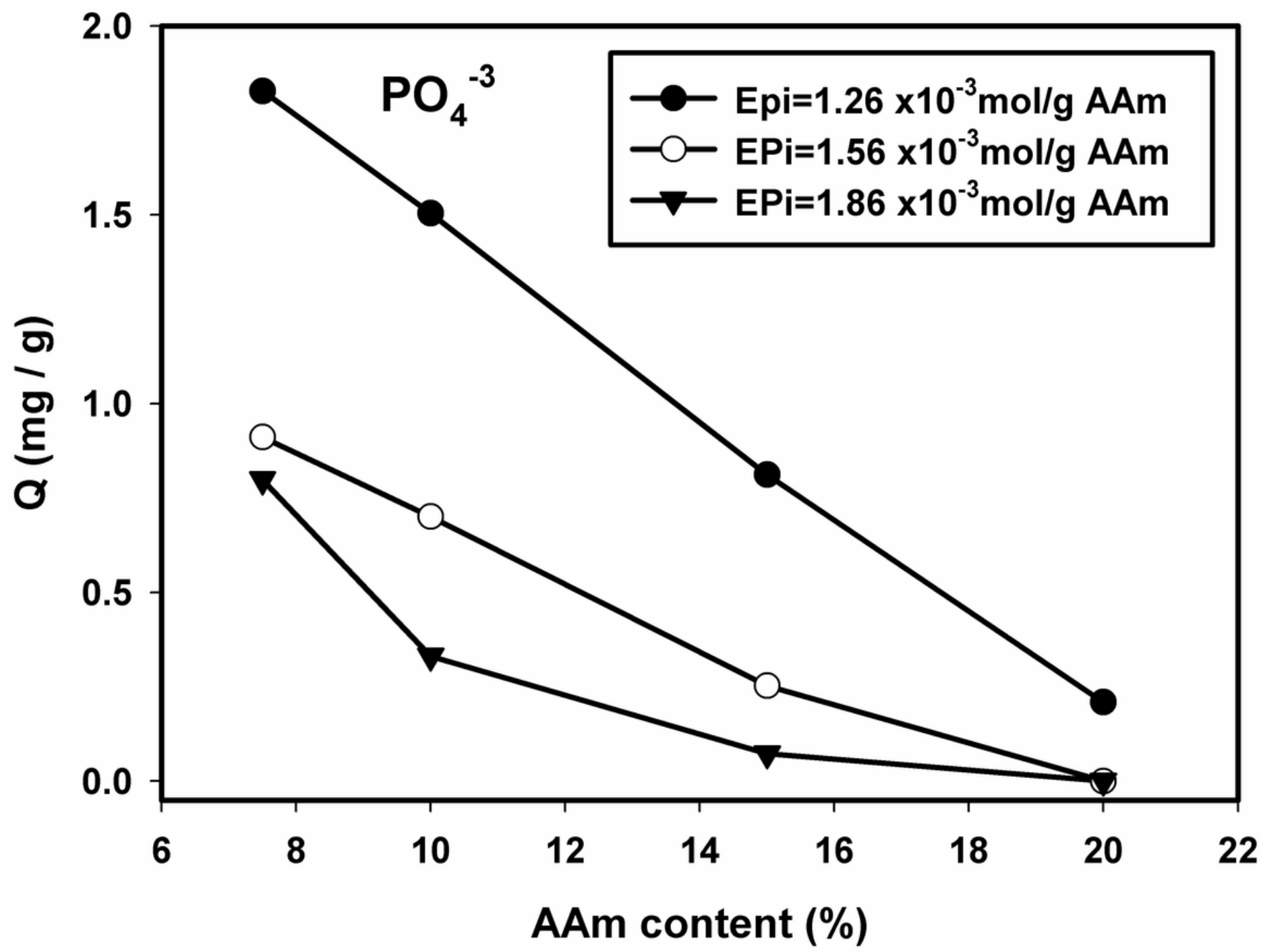

Figure 11

Effect of AAm and Epi contents on the adsorption capacity (Q) toward PO4 ions at irradiation dose 20 kGy after regeneration.

Figure 12

Adsorption isotherm of sulphate ions by $\mathrm{P}(\mathrm{AAm} / \mathrm{Epi})$ at different acrylamide and Epi contents after regeneration at $20 \mathrm{kGy}$. (A) Epi=1.26x10-3, (B) Epi=1.56x10-3 and (C) Epi=1.86x10-3

Figure 13

Adsorption isotherm of phosphate ions by $\mathrm{P}$ (AAm/ Epi) at different acrylamide and Epi contents after regeneration at $20 \mathrm{kGy}$. (A) Epi=1.26x10-3, (B) Epi=1.56x10-3 and (C) Epi=1.86x10-3 


\section{Supplementary Files}

This is a list of supplementary files associated with this preprint. Click to download.

- scheme1.tif 